\title{
The estimation of uranin (fluorescien sodium) in blood
}

\author{
T. WAGATSUMA AND HELEN PAYLING WRIGHT \\ From the Institute of Obstetrics and Gynaecology, \\ Hammersmith Hospital, London
}

SYNOPSIS The extraction and estimation of uranin (fluorescein sodium) in plasma is described. Heparin-plasma containing uranin is digested with crude ficin and extracted with acid n-pentanol. The supernatant fluid is re-extracted with $\mathrm{N} \mathrm{NaOH}$ and, after volume adjustment, read against a uranin standard in a fluorimeter with appropriate filters. It appears reliable within $4 \%$ at concentrations as low as $10^{-8} \mathrm{~g} . / \mathrm{ml}$.

The dye uranin (fluorescein sodium) is a non-toxic substance which offers considerable scope for measurements of the diffusibility of substances within the tissues, especially under circumstances in which radioactive isotopes are contraindicated. In spite of its advantages for such purposes, however, no satisfactory method has been devised for the estimation of this substance in the blood. Yet the possibility of determining its concentration in very dilute solutions is indicated by its use in studies of the circulation rate in which it is possible to detect by naked eye under ultra-violet light concentrations of fluorescein of the order of $10^{-5} \mathrm{~g} . / \mathrm{ml}$. in the vessels of mucous membranes.

The following method, elaborated and tested in this laboratory, makes it possible to detect the dye in concentrations of $10^{-10} \mathrm{~g} . / \mathrm{ml}$., though in our present work it is usually present in about $10^{-8} \mathrm{~g} . / \mathrm{ml}$. Estimations of a 'tracer' substance of this nature in dilutions of this order compare favourably with many isotope techniques and offers an alternative method of detecting the passage of materials from one compartment to another within the body. In our own work we are studying fluid exchanges between the mother and her conceptus. Uranin is injected transabdominally into the amniotic fluid of pregnant women during the last trimester and the rate of its passage into the maternal blood stream is measured. It is in such human subjects that the non-toxic and non-radioactive nature of this substance is of particular value.

\section{METHOD}

REAGENTS These are ficin (crude), concentrated $\mathrm{HCl}$ (s.g. 1·18), n-pentanol (ordinary grade), $\mathrm{N} \mathrm{NaOH}$, and methanol (AR standard).

PROCEDURE Heparin-plasma containing fluorescein is digested with ficin (1 mg. ficin/1 ml. plasma) for a minimum of 12 hours at $37^{\circ} \mathrm{C}$. or four hours at $56^{\circ} \mathrm{C}$. The digestion times are not critical and can be modified within broad limits as convenient. To $1 \mathrm{ml}$. of the digested plasma, acidified with one drop of concentrated $\mathrm{HCl}, 4 \mathrm{ml}$. of n-pentanol is added. The mixture is shaken vigorously for three minutes to precipitate any coagulable material and to extract the fluorescein; it is then centrifuged for five minutes at 2,000 to 2,500 r.p.m. The supernatant alcohol fraction, which contains the dye, is decanted into a stoppered separating funnel containing $1.5 \mathrm{ml}$. of $\mathrm{N} \mathrm{NaOH}$, again shaken vigorously and then allowed to separate. Care must be taken that separation is complete before running off the $\mathrm{NaOH}$ (lower) layer. The alcohol fraction is then re-extracted with a further $1 \mathrm{ml}$. of $\mathrm{NaOH}$ and, after separation, this is added to the first extraction giving a total of $2.5 \mathrm{ml}$. Of this, $2.0 \mathrm{ml}$. is added to $1.5 \mathrm{ml}$. of methanol to reduce turbidity. Thus the final volume is $3.5 \mathrm{ml}$., which gives a dilution factor of 4.375.

Since uranin shows maximal fluorescence in alkaline solution with the exciting wavelength between $4,600 \AA$ and $4,900 \AA$ and reading wavelength of $5,300 \AA$, the concentration of this dye in the extract is read on a Unicam spectrophotometer (SP 500) with a fluorimeter attachment (SP 550) fitted with Ilford filters no. 303 ( $\lambda$ maximum 4,800 $\AA$ ) on the excitation side and no. 404 ( $\lambda$ maximum $5,300 \AA$ ) for reading.

A standard of appropriate strength is made up in $\mathrm{N} \mathrm{NaOH}$ and methanol for comparison with the unknown sample.

\section{COMMENT}

Various modifications of this method have been 
examined to find whether they offer any improvement on the above technique. It has been found that the anticoagulants, oxalate and citrate, give rather worse recovery rates than heparin, a finding that may be due to the effects of the rise in the concentration of sodium ions when these substances are used. The interval between the withdrawal of the blood from the patient and the separation of its cells was immaterial as long as haemolysis did not occur. The possibility that error might arise from haemolysis was examined, and small degrees of red cell breakdown, just visible to the naked eye, were found to have no effect on the estimation of the uranin. When haemolysis is gross, however, the yellow pigment carried into the final solution gives a falsely high reading in the fluorimeter.

The effect of bacterial contamination was studied to ascertain the need for keeping the specimens sterile before extraction. Samples of fluorescein-containing plasma were inoculated with $E$. coli, incubated for 36 hours, and the dye then extracted. In spite of the turbidity caused by the bacteria, their growth had no influence on the subsequent estimation of uranin. It has been found, however, that organisms that produce colour changes in the plasma may, as with haemolysis, interfere $\frac{\mathbb{0}^{\frac{0}{\sigma}}}{\text { with the estimation. }}$
with

Since fluorescein sodium may become linked to $\overrightarrow{\vec{F}}$ the proteins of the plasma, and especially the $\stackrel{5}{\rightarrow}$ albumin fraction, the recovery rates before and $\frac{O}{2}$ after breakdown of the protein molecule with the $\frac{\overline{\bar{D}}}{\bar{\rho}}$ proteolytic enzyme, ficin, were compared. The $\frac{\bar{\phi}}{\partial}$ digested plasma yielded a better recovery, with a $\propto$ smaller range of variation than the untreated क samples. Separation of the dye from the plasma $\vec{\circ}$ proteins was attempted by various precipitation methods (heat, propanol, methanol, $\mathrm{ZnSO}_{4}, \vec{\omega}$ $\mathrm{Na}_{2} \mathrm{WO}_{4}$ ); none was satisfactory.

The repeatability of the method has been examined. $\frac{\bar{O}}{0}$ With plasma samples in which the uranin con- $\vec{v}$ centrations range from $10^{-6}$ to $10^{-8} \mathrm{~g} . / \mathrm{ml}$., the $\omega$ variation of duplicates is within $4 \%$. Finally, the recovery rate was studied. With samples of plasma, to which known amounts of fluorescein sodium have been added, it has been found that with this method an average of $80 \%$ of the dye is recovered, and that the variation round this figure is small. The correction factor of 1.25 may therefore bec applied if absolute rather than relative estimations? of uranin in the plasma are required. 